\title{
O PAPEL DO PROFISSIONAL DE SAÚDE FRENTE À VIOLÊNCIA E MAUS TRATOS NA INFÂNCIA
}

Fernando Sala Marin ${ }^{1}$, Lyara Meira Marinho Queiróz ${ }^{1}$, Thamires Calé Corrêa ${ }^{1}$, Thalita Campos Aparecido $^{1}$, Caroline Hirayama ${ }^{1}$, Marcos Barbosa Tavares Filho ${ }^{1}$, Vinícius Pereira Perassol ${ }^{1}$, Genaina de Oliveira ${ }^{1}$, Rita de Cassia Ramos Medeiros ${ }^{1}$, MEDEIROS, Giselle Orosco Takara de ${ }^{1}$; GONÇALVES, Priscila Assis ${ }^{1}$; BACCO, Anette Bocchi ${ }^{1}$; PANDINI, Marcelo Dal Belo ${ }^{1}$; UTINO, Elza Akiko Natsumeda

${ }^{1}$ Universidade do Oeste Paulista - UNOESTE, Curso de Medicina. ${ }^{2}$ Departamento de Pediatria, Presidente Prudente, SP.

\section{RESUMO}

A violência contra crianças e adolescentes é um grave problema mundial e pode ser definida como um dano intencional praticado por um sujeito que se encontre em condição de superioridade capaz de causar dano físico, psicológico ou sexual, contrariamente à vontade da vítima. Assim, o presente trabalho tem como objetivo demonstrar a importância da atuação dos profissionais de saúde frente a casos suspeitos ou confirmados de violência nessa faixa etária. Utilizaram-se artigos indexados nas bases eletrônicas Pubmed, MEDLINE, SciELO e LILACS, selecionados 16 artigos científicos compreendendo o período de 1999 a 2014. Estes revelaram que, embora a legislação seja clara quanto à obrigatoriedade da notificação, existem entraves que a permita, como escassez de regulamentos que firmem os procedimentos técnicos, falha na identificação da violência no serviço de saúde e quebra de sigilo profissional. Deste modo, é preciso que os profissionais da área estejam preocupados a identificar sinais de maus tratos.

Palavras-chave: Violência. Violência doméstica. Maus tratos infantis. Violência contra a criança. Síndrome da criança maltratada

\section{THE ROLE OF HEALTHCARE PROFESSIONALS TOWARDS CHILDHOOD VIOLENCE AND ABUSE}

\begin{abstract}
The violence against children and adolescents is a serious global problem and can be defined as an intentional damage which is done by a person who is in a superiority condition capable of causing physical, psychological or sexual harm, contrary to the will's victim. Thus, this paper aims to demonstrate the importance of healthcare professionals work in suspected or confirmed violence in this age group. Were used articles indexed in electronic databases PubMed, MEDLINE, SciELO, LILACS, being selected 16 papers covering the period 1999-2014. They showed that law is clear on the obligation of health professionals to notify, but there are several obstacles, as the lack of regulations for technical procedures in this cases, the failure in violence identification at health service and the professional secrecy break. Thus, it is important that professionals are concerned and able to identify signs of abuse.

Keywords: Violence. Domestic violence. Child abuse. Violence against children. Battered child syndrome.
\end{abstract}




\section{INTRODUÇÃO}

A violência contra crianças e adolescentes é um grave problema mundial, que atinge e prejudica esta população que está em período de desenvolvimento ${ }^{1}$. No seu sentido mais amplo, a violência abrange causas externas, acidentais e intencionais, enquanto que em seu sentido mais estrito se refere especificamente à dano intencional, descrito frequentemente pelos seus sinônimos de agressão, maus-tratos ou abuso ${ }^{2}$.

Apesar de a violência familiar ser descrita desde a antiguidade, somente há cerca de 30 anos é que o tema vem sendo sistematicamente discutido por pesquisadores da área de saúde. A importância dada ao problema, não só no meio acadêmico como também na imprensa e no restante da sociedade civil, é consequência direta das estatísticas alarmantes encontradas ao longo dos últimos anos ${ }^{3}$.

Mundialmente, quase 3.500 crianças e adolescentes morrem anualmente por maus-tratos (físico ou negligência). Para cada morte por maus-tratos em menores de 15 anos, estimam-se 150 casos de abuso físico. No mundo todo, calcula-se um coeficiente de mortalidade por maus-tratos de 2,2 por 100.000 crianças do sexo feminino e de 1,8 por 100.000 crianças do sexo masculino, sendo os maus-tratos perpetrados pelo pai biológico (em 41,3\% dos casos), pela mãe biológica $(38,9 \%)$, pelo padrasto $(11,1 \%)$, pela madrasta $(3,4 \%)$, por outros parentes $(4,9 \%)$ e por famílias e parentes adotivos $(0,4 \%)^{4}$.

As modalidades de violência doméstica, cometidas contra crianças e adolescentes, são classificadas em: violência física, violência psicológica, negligência e violência sexual. Essas modalidades podem ocorrer na forma pura, quando se trata de uma única modalidade de violência, ou associada, quando em um mesmo caso são identificadas duas ou mais modalidades ${ }^{5}$.

O tipo mais frequente de maus-tratos contra a criança ou adolescente no Brasil é a violência doméstica, que ocorre na maioria das vezes dentro dos lares ou no convívio familiar ${ }^{6}$. Vale ressaltar que a violência doméstica não acontece exclusivamente nas classes menos favorecidas, atingindo famílias de todas as camadas sociais, independentemente de situação sócio econômica, raça, religião ou nível intelectual. Contudo, é nas classes menos favorecidas que a violência se torna mais evidente, devido ao maior controle pelas autoridades policiais e a maior procura às delegacias ${ }^{7,8}$.

No Brasil, o conhecimento sobre a dimensão da violência é ainda escasso, em decorrência da dificuldade estatística e do atendimento de maus tratos pouco estruturado no país, não sendo possível conhecer a sua magnitude real ${ }^{9}$. 
O Ministério da Saúde (MS) aponta que as agressões constituem a primeira causa de morte de jovens entre 5 e 19 anos de idade, sendo que a maior parte dessas agressões provém do ambiente doméstico ${ }^{10}$. Ademais, é importante reconhecer que a maioria das estimativas existentes na área reflete somente os casos mais visíveis e/ou graves de violência familiar ${ }^{3}$.

Em nosso país, os maus tratos passam a ser tratados como objeto de notificação obrigatória, previsto no Artigo 227 da Constituição Federal (BRASIL, 1988) e no Artigo 13 do Estatuto da Criança e do Adolescente (ECA) ${ }^{11}$, "prevendo penas para os médicos, professores e responsáveis por estabelecimentos de saúde e educação que deixassem de comunicar os casos de seu conhecimento (art. 245)".

Para que a violência contra a criança comece a diminuir, é preciso que a criança seja vista, respeitada e tratada como um ser humano, sujeito de sua história de vida, sendo-lhe dada a capacidade de pensar, agir e reagir ante as adversidades do meio em que vive. Somente a partir desse momento será verdadeiramente respeitada ${ }^{7}$.

Os dados atualmente disponíveis indicam que a violência contra crianças é um importante problema na Saúde Pública, e o que se observa é um despreparo dos profissionais na identificação e atuação adequada sobre casos onde há suspeita de maus tratos ${ }^{6}$. Sabemos, no entanto, que a identificação e a ação efetiva destes é um dos fatores que pode contribuir de forma significativa para reduzir esse problema. Desta forma, este trabalho tem como objetivo demonstrar a importância da atuação adequada dos profissionais de saúde frente a casos suspeitos ou confirmados de violência e maus tratos na infância.

\section{METODOLOGIA}

Trata-se de uma revisão bibliográfica, onde buscou-se artigos indexados nas bases eletrônicas Pubmed, MEDLINE - Literatura Internacional em Ciências da Saúde, SciELO ScientificElectronic Library Online e LILACS - Literatura Latino-Americana, consultados a partir do portal de base de dados livres e restrito da biblioteca virtual da Universidade do Oeste Paulista (Unoeste), entre o período de 1999 a 2014, sendo selecionados os que melhor abordavam o tema central desta.

Os descritores utilizados foram "violência", "violência doméstica", "maus tratos infantis", "violência contra a criança", "síndrome da criança maltratada", sendo utilizados 16 artigos. 


\section{RESULTADOS}

Os maus tratos ou abuso ocorre quando um sujeito em condições de superioridade (idade, força, posição social ou econômica, inteligência, autoridade) comete um ato ou omissão capaz de causar dano físico, psicológico ou sexual, contrariamente à vontade da vítima, ou por consentimento obtido a partir de indução ou sedução enganosa ${ }^{12}$.

A violência contra crianças e adolescentes pode afetar todos os aspectos da vida da criança, não devendo ser desconsiderado o efeito em longo prazo do trauma infantil, que muitas vezes não são evidenciados de imediato. Deve ser reconhecido como um sério problema da infância. Mesmo com a retirada das crianças vitimadas de suas casas ou mantidas longe do agressor, os efeitos da experiência vivida repercutirão em toda sua vida ${ }^{13}$.

A violência é uma resposta à outra violência exercida anteriormente. Muitos dos agressores que praticam atos violentos contra a família, em especial contra a criança, presenciaram ou até foram vítimas de violência e maus-tratos durante a infância ou adolescência. É uma questão de causa e efeito, pois nenhuma pessoa considerada mentalmente saudável mantém atitudes agressivas e violentas pelo simples prazer de praticá-las ${ }^{7}$.

No Brasil, os maus tratos contra a criança só passaram a merecer maior atenção no final dos anos 80, com o texto da atual Constituição Brasileira, que assegura direitos à criança e ao adolescente, deixando de ser vistos como propriedade dos pais ${ }^{6}$. Desde então, o conhecimento sobre essa forma de violência vem sendo ampliado e sua gravidade reconhecida, ainda que os dados globais sobre sua magnitude não estejam devidamente dimensionados, pois a subnotificação ainda impossibilita conhecer melhor a grandeza do problema, o perfil da vítima e do agressor ${ }^{2,5}$.

Para garantir os direitos dessa população, foi criada em 13 de julho de 1990 a Lei Federal 8.069 que dispõe sobre o Estatuto da Criança e do Adolescente (ECA), onde ficam assegurados direitos especiais e proteção integral à criança e ao adolescente. Além disso, o ECA tornou compulsória a notificação, por parte do profissional de saúde, de casos suspeitos ou confirmados de maus tratos contra crianças e adolescentes atendidos no sistema público de saúde ou em consultórios particulares ${ }^{6,7}$.

Foi publicado ainda no Diário Oficial da União, a criação da Ficha de Notificação Compulsória de Maus-Tratos Contra Criança e Adolescente, a partir da portaria 1968, de 25 de outubro de 2001, pelo Ministério da Saúde (MS), fundamentada nos artigos 13 e 245 do ECA ${ }^{5}$. Por previsão expressa deste último, será penalizado com multa o profissional de saúde que deixar de 
comunicar à autoridade competente os casos envolvendo suspeita ou confirmação de maus tratos contra criança ou adolescente ${ }^{14}$.

Não basta, porém, que crianças e adolescentes tenham seus direitos assegurados em leis, é preciso que essas leis sejam efetivadas na prática ${ }^{7}$. A legislação brasileira, embora clara quanto à obrigatoriedade de notificar, oferece pouca orientação aos profissionais. Estima-se que, para cada caso notificado, 10 a 20 deixam de ser $^{6}$.

No Brasil, a padronização para registrar situações de violência familiar é fragmentada, o que gera prejuízo para uma rotina clara e eficaz, ocasionando déficits nos procedimentos a serem seguidos pelos profissionais e instituições. Além do mais, há carência de políticas públicas eficazes que viabilizem a criação e, principalmente, a manutenção de programas preventivos e de tratamento, indispensáveis para promover o aprimoramento e evolução de técnicas eficazes no enfrentamento dessa problemática ${ }^{5}$.

Um dos problemas para a subnotificação é o fato dos profissionais de saúde terem dificuldade para identificar os casos, por falta de informações básicas que permitam o diagnóstico. É de fundamental importância a habilidade de diferenciar indícios de maus-tratos de outras doenças, tais como: ${ }^{6}$

- Lesões que não se justificam pelo tipo de acidente relatado e que são incompatíveis com a idade (Exemplos: fratura de crânio por bater a cabeça no berço, fratura de perna em crianças com idade inferior a um ano);

- Lesões como equimoses, lacerações, hematomas, fraturas, queimaduras e mordeduras;

- $\quad$ Lesões em vários estágios de cicatrização ou cura;

- Lesões em áreas não comuns de acidentes e quase sempre cobertas, como genitália e nádegas;

- Demora para procurar atendimento médico após o acidente;

- Crianças em situação de higiene precária, como vestuário sujo e inapropriado ao clima local.

Portanto, a suspeita e denúncia são importantíssimas estratégias de manejo, no sentido de afastar a criança ou adolescente do agressor. Entretanto, a suspeita ou confirmação de abusos ou maus-tratos ainda é um desafio para os profissionais da saúde, principalmente por falta de informações técnicas e científicas, já que a maioria das disciplinas da saúde não contempla em seus currículos e programas de educação continuada, a formação e o treinamento dos aspectos 
relacionados com a violência. Existindo assim a necessidade urgente de incluir o tema nos currículos e capacitar os profissionais já graduados ${ }^{6,14}$.

Além disso, existem vários outros entraves à notificação no Brasil, como escassez de regulamentos que firmem os procedimentos técnicos para isso, ausência de mecanismos legais de proteção aos profissionais encarregados de notificar, falha na identificação da violência no serviço de saúde e a quebra de sigilo profissional. Sendo que a comunicação constitui justa causa para o rompimento deste último, e poderá ser feita à autoridade judicial nos locais onde não houver o Conselho Tutelar ${ }^{14}$.

Outro entrave à notificação diz respeito aos próprios Conselhos Tutelares, órgãos designados pelo ECA para receber as comunicações de casos suspeitos ou confirmados de maustratos. Afirmando que estes não estão implementados em todos os municípios brasileiros, e mesmo onde instalados, funcionam muitas vezes em condições adversas: com falta de infraestrutura, precariedade de serviços que possibilitem a execução das medidas aplicadas, formação heterogênea dos conselheiros e uma grande demanda de serviços. Também pode ser considerado um obstáculo as próprias famílias envolvidas, que podem tentar impedir a notificação, fornecendo ou negando informações que fundamentem as suspeitas, por se sentirem ameaçadas pelo ato de notificar.

O baixo grau de confiança nos órgãos de proteção tem sido fator relacionado com a não notificação, mesmo em países de notificação mandatória e com sistema de proteção adequado. Outro ponto que deve ser levado em consideração para subnotificação, é que quando o profissional atua no setor privado, onde o envolvimento emocional e aspectos financeiros, bem como o medo de envolvimento legal, inibiriam atitudes proativas em relação à notificação de casos de maus-tratos infantis ${ }^{6}$.

Todo esse processo, que vai do diagnóstico à notificação e à tomada de decisões sobre como proteger a vítima e atuar junto ao agressor, é uma construção coletiva de todos os que acreditam na possibilidade de modificar o quadro cultural e social da violência contra a criança e o adolescente $^{12}$.

Portanto, é necessário a conscientização da sua importância, a quebra de ideias préconcebidas e o treinamento correto para diagnosticar situações de violência pelo profissional de saúde, tornando-se capaz de detectar e notificar, a quem for competente, essa realidade que se apresenta de forma tão expressiva no cotidiano dos seus atendimentos ${ }^{14}$. 


\section{CONCLUSÃO}

A violência contra crianças e adolescentes se torna cada vez mais presente no nosso cotidiano e os dados atuais mostram que se trata de uma causa importante de morbimortalidade nessa população, sendo considerado um problema em Saúde.

Deste modo, é preciso que os profissionais da área estejam preocupados e aptos a identificar sinais de possíveis maus-tratos sabendo conduzir esses casos adequadamente, sendo assim decisivos na minimização do sofrimento das vítimas e dessas famílias.

Portanto, a notificação de casos suspeitos e confirmados de agressões é um poderoso instrumento de política pública assegurada por lei, dando início a um processo que se caracteriza muito mais como assistência e auxílio do que como punição, colaborando com trabalhos de pesquisa que demonstrem a real dimensão da problemática e, consequentemente, proporcionando melhoria na qualidade dos programas de intervenção.

\section{REFERÊNCIAS}

1. Pires JM, et al. Barreiras, para a notificação pelo pediatra, de maus-tratos infantis. Rev Bras Saude Mater Infant. 2005; 5(1): 103-108. DOI: http://dx.doi.org/10.1590/S151938292005000100013

2. Martins CBG. Maus tratos contra crianças e adolescentes. Rev Bras de Enferm. 2010 julago; 63(4): 660-5. DOI: http://dx.doi.org/10.1590/S0034-71672010000400024

3. Reichenheim ME, Hasselmann MH, Moraes CL. Consequências da violência familiar na saúde da criança e do Adolescente: contribuições para a elaboração de propostas de ação. Cienc saúde coletiva. 1999; 4(1): 109-121. DOI: http://dx.doi.org/10.1590/S1413-81231999000100009

4. Martins CBG, Jorge MHPM. A violência contra crianças e adolescentes: características epidemiológicas dos casos notificados aos Conselhos Tutelares e programas de atendimento em município do Sul do Brasil. Epidemiol Serv Saúde. 2002 e 2006 dez; 18(4): 315-334. DOI: http://dx.doi.org/10.5123/S1679-49742009000400002

5. Brito $\mathrm{AM}$ et al. Violência doméstica contra crianças e Adolescentes: estudo de um programa de intervenção. Cienc saúde coletiva. 2005 mar; 10(1): 143-149. DOI: http://dx.doi.org/10.1590/S1413-81232005000100021

6. Pires ALD, Miyazaki MCOS. Maus tratos contra crianças e adolescentes: revisão de literatura para profissionais da saúde. Arq De Ciências da Saúde [Internet]. 2005 jan-mar; 12(1): 42-9 [acesso em 6 fev 2015]. Disponível em: https://www.nescon.medicina.ufmg.br/biblioteca/imagem/2733.pdf

7. Biasil LS, Penna C MM. Violência e maus-tratos na infância: o olhar das crianças. Rev Min Enf [Internet]. 2004 out-dez; [acesso em 5 fev 2015];8(4):429-435. Disponível em: http://www.reme.org.br/artigo/detalhes/701. 
8. Granville-Garcia AF, Menezes VA, Silva PFRM. Maus tratos infantis: Percepção e responsabilidade do cirurgião-dentista. Rev Odontol [Internet]. 2008 [acesso em 22 fev 2015]; 23(1): 35-39. Disponível em:

http://revistaseletronicas.pucrs.br/fo/ojs/index.php/fo/article/viewFile/1112/2869.

9. Oliveira VLA, Ribeiro CR, Albuquerque C. Notificação obrigatória da violência ou suspeita de violência contra crianças e adolescentes: construindo uma rede de proteção. Divulg Saúde Debate. [Internet]. 2003. [acesso em $7 \mathrm{fev}$ 2015]. Disponível em: http://bases.bireme.br/cgibin/wxislind.exe/iah/online/?lsisScript=iah/iah.xis\&src=google\&base=LILACS\&lang=p\&nextAction= Ink\&exprSearch=385114\&indexSearch=ID

10. Brasil, Ministério da Saúde. Notificação de maus tratos contra crianças e adolescentes pelos profissionais de saúde: um passo a mais na cidadania em saúde. Brasília (DF): Ministério da Saúde, Secretaria de Assistência à Saúde. [Internet]. 2002. [acesso em 6 fev 2015]. Disponível em://bvsms.saude.gov.br/bvs/publicacoes/notificacao_maustratos_criancas_adolescentes.pdf

11. Brasil. Lei no 8069, de 13 de julho de 1990. Dispõe sobre o Estatuto da Criança e do Adolescente e dá outras providências. [Internet]. [acesso em 5 fev2015]. Disponível em: http://www.planalto.gov.br/ccivil_03/LEIS/L8069.htm

12. SBP Sociedade Brasileira de Pediatria. Guia de atuação frente a maus tratos na infância e adolescência: orientação para pediatras e demais profissionais de saúde. [Internet]. 2001 [acesso em 6 fev 2015]. Disponível em: http://177.43.101.79/content/userfiles/image/imagebank/maustratos_sbp.pdf 13. Day VP et al. Violência doméstica e suas diferentes manifestações. Rev psiquiatr. 2003 abr; 25(1): 9-21. DOI: http://dx.doi.org/10.1590/\$0101-81082003000400003

14. Saliba $O$ et al. Responsabilidade do profissional de saúde sobre a notificação de casos de violência doméstica. Rev Saúde Pública. 2007 jun; 41(3): 472-7. DOI: http://dx.doi.org/10.1590/S0034-89102007000300021 